\title{
ORGANIZAÇÃO DO CONHECIMENTO EM SHORTCUTS: MEMÓRIAS DE PESQUISA SOB O SPRIT BENJAMINIANO
}

\author{
ORGANIZACIÓN DEL CONOCIMIENTO EN \\ SHORTCUTS: MEMORIAS DE INVESTIGACIONES BAJO \\ EL SPRIT BENJAMINIANO
}

Vera Dodebei *

\begin{abstract}
RESUMO
Introdução: Sob a metáfora da 'árvore de mãos dadas', discute-se os conceitos, os meios de transmissão e os usos dos registos memoriais em quatro atalhos, passagens, passarelas ou shortcuts de natureza temporal e histórica: filosofia, ciência, informação e ecologia. Objetivos: discutir memórias de pesquisas no campo da Organização do Conhecimento. Metodologia: O estudo adotou as redes de relações conceituais construídas por mapas com o apoio do software CmapTools para o desenvolvimento da análise e da discussão teórica. Resultados: Como resultados principais, apresenta indicadores e pressupostos de que já há uma mudança, em relação ao compromisso social de compartilhar memórias por parte das instituições armazenadoras de conhecimentos. Conclusões: a observação de que a qualidade dos dados a serem escolhidos para alimentar coleções de objetos selecionados como memória deverá levar em conta o modo como os objetos digitais foram criados: dados fluidos ou de caráter meramente comunicacional e, portanto, efêmeros; ou dados protegidos por camadas de informações que assegurem sua autenticidade com propósito de reuso memorial.
\end{abstract}

Palavras-chave: Organização do Conhecimento. Memória. Objeto digital.

1 INTRODUÇÃO: EXPERIÊNCIA, MEMÓRIA E CONHECIMENTO

Para o Colóquio em Organização do Conhecimento "A pesquisa brasileira e os cenários contemporâneos", organizado por Rosali Fernandez de Souza e Gustavo Saldanha sob a chancela do Instituto Brasileiro de * Doutora em Comunicação e Cultura. Professora Titular da UNIRIO. E-mail: dodebei@gmail.com.

Inf. Inf., Londrina, v. 22, n. 2, p. 67 - 83, maio/ago., 2017. 
Informação em Ciência e Tecnologia (IBICT), realizado em julho 2016, tive a honra de abrir o evento, o que muito me emocionou. A conferência transcrita aqui representa, com pequenos ajustes para a versão escrita, não um texto teórico ou um relato de pesquisa específica, mas uma narrativa de minha experiência como pesquisadora por mais de trinta anos sobre o tema da Organização do Conhecimento. Preferi reunir imagens (sinaléticas) que simbolizam rupturas e continuidades epistemológicas do campo, ao mesmo tempo em que sintetizam a minha experiência pessoal como pesquisadora.

Sobre a estrutura quase artesanal dos tesauros na década de 70 do século $X X$, pesquisamos como essas construções lógicas ainda hoje são essenciais aos invisíveis crawlers na internet que respondem a perguntas feitas, ao mesmo tempo em que vigiam os pesquisadores sob a ótica do consumo. A estratégia discursiva para memorar o campo da Organização do Conhecimento $(\mathrm{OC})$ pauta-se na imagem da passarela, dos shortcuts ou das passagens sobre as quais Walter Benjamin vai descrever a Paris da Modernidade. Passagens nos levam de um ponto espacial ou temporal a outro de modo mais rápido. Assim como as dobras do tempo em buracos negros que estreitam pontos de passagem para outra época, esses pontos são aqui representados pelos objetos de pesquisa que vimos desenvolvendo em OC. O que são passagens, shortcuts, passarelas ou atalhos para Benjamin? (2007).

A coleção dos fragmentos aparentemente desconexos, em obra inacabada, escrita por Benjamin entre 1927 e 1940, ano de sua morte, mostra a sua experiência intelectual e espaciotemporal em relatos sobre a Paris do século XIX, com foco nas estruturas de ferro e vidro que constituem as arcadas parisienses. Do ponto de vista espacial, as arcadas eram lugares de passagem, já que com a reforma arquitetônica da cidade feita pelo Barão de Haussman, as grandes avenidas de Paris dificultavam o acesso transversal por seus transeuntes.

Quanto ao aspecto temporal, havia nessas passarelas uma explosão de vida. Memórias de todos os tipos emanadas de objetos "fora de moda" de um tempo que se modificava rapidamente no âmbito da tecnologia e que podiam

Inf. Inf., Londrina, v. 22, n. 2, p. 67 - 83, maio/ago., 2017. 
Vera Dodebei

Organização do conhecimento em shortcuts: memórias de pesquisa sob o sprit benjaminiano

ser achados em brechós, livrarias e cafés, o que proporcionava ao flaneur uma ponte do presente ao passado e em direção ao futuro da Modernidade. $O$ manuscrito contendo a coleção de fragmentos sobre essa época foi entregue por Benjamin ao amigo George Bataille, bibliotecário da Biblioteca Nacional. George Bataille o escondeu em um arquivo fechado, descoberto apenas depois da Segunda Guerra Mundial.

A experiência benjaminiana sobre as passagens levou-me a organizar minha memória em marcos de pesquisa tanto afetivos quanto de mudanças paradigmáticas, ou revoluções, no entender de Thomas Kunh (2001). No que tange à Organização do Conhecimento, pode-se indicar quatro "passagens: (1) classificações (filosofia); (2) tesauros (ciência); (3) ontologias (informação); e, (4) Big data (ecologia). Essas "passarelas" são construídas não somente em função aos avanços das tecnologias de informação e comunicação, como também às mudanças sociais e de interconhecimentos que abrem espaço para intensos diálogos entre disciplinas científicas ao lado de saberes tradicionais, modificando drasticamente o modo de conhecer e representar o mundo ao longo do século $X X$.

A organização dos registros da cultura humana, seus feitos, sua história, sua memória são patrimônios construídos por gerações. Quer seja, metaforicamente, no âmbito das mitologias a exemplo das figuras de Hermes (movimento e tempo) e Hera (centro, Gaia no equilíbrio do kaos), quer seja nas cosmogonias dos povos ancestrais, o conhecimento, razão de disputas entre os seres, cada vez mais se torna motivo de lutas acirradas sob o domínio do poder sobre o saber. $O$ legado que cada geração deixa de herança para o futuro segue um curso entre a transmissão transgeracional via oralidade por um lado e, por outro, via os registros e as inscrições reprodutíveis que permitem aos humanos refletir sobre suas atuações e experiências de vida neste pequeno planeta, em meio ao vasto universo ainda desconhecido.

O recorte espaciotemporal que ora apresentamos sobre o tema da Organização do Conhecimento é um acontecimento ínfimo mas, ao mesmo tempo, é uma contribuição para compreendermos os esforços feitos por

Inf. Inf., Londrina, v. 22, n. 2, p. 67 - 83, maio/ago., 2017. 
estudiosos e pesquisadores sobre como transmitir e criticar o que foi realizado pela experiência humana. Assim, o foco para este complexo contexto considera, sob a metáfora da árvore de mãos dadas, os conceitos dominantes, os meios de transmissão e os usos dos registos memoriais em quatro atalhos, passagens, passarelas ou shortcuts de natureza histórica: Filosofia, Ciência, Informação e Ecologia.

Figura 1 - Árvores de Mãos Dadas

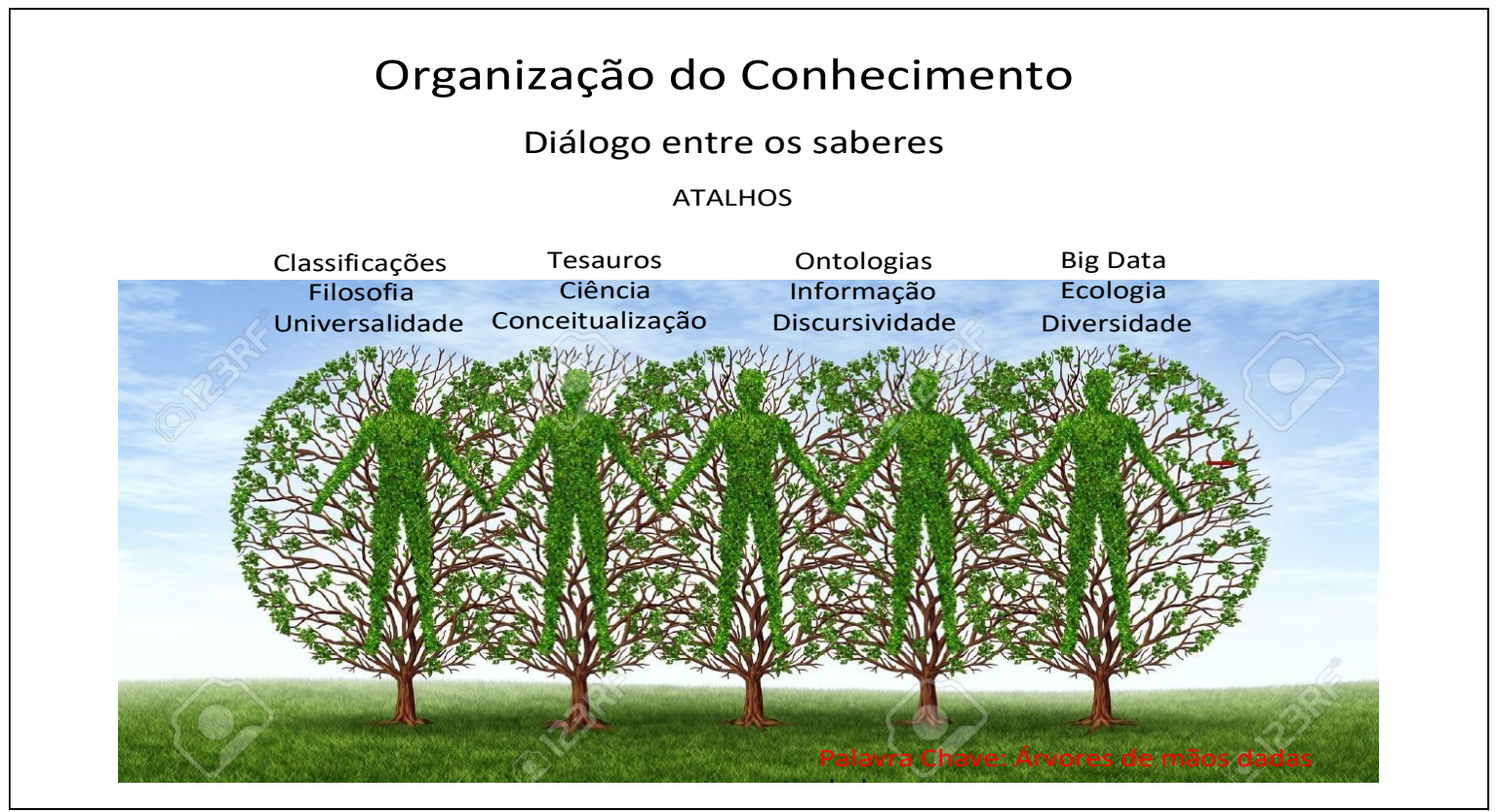

Fonte (com adaptações da autora): https://www.google.com.br

Tentarei, de modo breve, discutir nos próximos itens o mapa aqui construído, sempre tendo em vista a memória do conhecimento e das práticas de organização de coleções em bibliotecas.

\section{LÓGICA DO ASSUNTO: CLASSIFICAÇÕES, FILOSOFIA, UNIVERSALIDADE}

Assim como os rolos de papiro e os códices eram organizados por autor, data ou assuntos, as classificações bibliográficas, inspiradas nas classificações filosóficas, ganham notoriedade com o advento dos esquemas universais em

Inf. Inf., Londrina, v. 22, n. 2, p. 67 - 83, maio/ago., 2017. http:www.uel.br/revistas/informacao/ 
que o universo do conhecimento é dividido em classes. As classificações decimais, nos exemplos da Classificação Decimal de Melvil Dewey (18511931) e da Classificação Decimal Universal de Paul Otlet e Henri la Fontaine (final do século XIX), até hoje são utilizadas para organizar o acervo de bibliotecas por grandes assuntos. Há que ressaltar que as coleções de livros em bibliotecas públicas na década de setenta do século passado eram ainda organizadas por tamanho do livro - caso da Biblioteca Estadual do Rio de Janeiro - onde realizei minha primeira experiência como estagiária em Biblioteconomia.

As classificações decimais, ainda em uso em nossas bibliotecas, servem como indicadores temáticos normativos mas, ainda assim, não atendem à diversidade dos campos culturais do mundo atual. No exemplo da Colon Classification elaborada por Ranganathan (1933), de natureza universal, vimos que a experiência transformou o modo de pensar dos classificacionistas mas também não se aplicou às culturas fora da India. No entanto, esses esquemas universais serviram de inspiração para a representação de domínios, como, por exemplo, a Classificação Brasileira de Ocupações.

Minha primeira experiência com a pesquisa foi no projeto PNUD/BRA/550 para a elaboração da Classificação Brasileira de Ocupações (CBO). A CBO, adaptada da Classificação Internacional Uniforme de Ocupações (CIUO), foi um projeto da Organização Internacional do Trabalho (OIT), criado para auxiliar os países em desenvolvimento a cartografarem sua força de trabalho. Certamente, a página atual online da CBO mostra a influência até hoje da 'lógica do assunto' e da estrutura decimal para o arranjo das classes, subclasses, grupos e subgrupos, até chegar à descrição das tarefas relativas ao posto de trabalho, que representa a ínfima espécie na cadeia de gêneros e espécies ocupacionais (BRASIL. Ministério do Trabalho,1977).

Um exemplo sobre essa facilidade de compreensão da linguagem de representação proporcionada pelas classificações decimais é a do arranjo físico dos livros impressos em bibliotecas. Ao visitar Trinidad (Patrimônio da

Inf. Inf., Londrina, v. 22, n. 2, p. 67 - 83, maio/ago., 2017. 
Humanidade), cidade do interior de Cuba, por ocasião da Feira Nacional de Livros, entrei na Biblioteca Municipal e fui recepcionada por uma bibliotecária que me perguntou de onde eu era, ao que afirmei, do Brasil. A bibliotecária me disse que tinha em seu acervo obras de literatura brasileira e que me levaria à estante onde estas se encontravam. Disse a ela que não precisava pois já tinha observado que o acervo estava classificado pela Classificação Decimal de Dewey e que literatura brasileira era notacionalmente classificada na classe 869.

As classificações decimais universais permitem, assim, que sistemas e arranjos possam ser comparados e compartilhados, tanto em bibliotecas, quanto em campos de conhecimento diversos.

3 LÓGICA DO CONCEITO: TESAUROS, CIÊNCIA E CONCEITUALIZAÇÃO

Em 1975 fiz a seleção para cursar o mestrado em Ciência da Informação, no IBICT, e defendi a dissertação: "Construção de Thesauri: experimento empírico para a coleta de termos em formação profissional". Naquela época, os tesauros já existiam em áreas de pesquisa de ponta como o Engineering Joint Council - EJC, o International Nuclear Information System INIS, entre outros. O que me seduziu na pesquisa-dissertação foi 0 experimento metodológico em relação à escolha dos conceitos-chave que organizam um determinado domínio de conhecimento.

O uso conjunto da literatura especializada e da opinião dos produtores e usuários daquelas informações, em outras palavras, as garantias literárias e dos usuários já acenavam, naquela ocasião, para o que, hoje, conhecemos como indexação feita pelos usuários, folksonomias, indexação e representação compartilhadas. Tais princípios, relevantes por recortar o universo conceitual de um determinado campo de conhecimento, já eram, nas décadas de sessenta e setenta do século passado, um indício da importância da análise de

Inf. Inf., Londrina, v. 22, n. 2, p. 67 - 83, maio/ago., 2017. 
comunidades discursivas para melhor representar e recuperar informações. E o modelo de linguagem documentária nessa fase é, de fato, o do tesauro.

Ao Roget'sThesaurus (1852), que inspirou os bibliotecários a utilizar este instrumento para organizar e disseminar o conhecimento, são dedicados vários endereços na Internet, não só com conteúdos históricos, mas com as edições recentes do tesauro para consulta em tela. O campo ou domínio desse tesauro é a língua inglesa e seu propósito continua a ser aquele imaginado por Roget em 1850 ou seja, o de auxiliar na escolha de uma expressão que melhor reflita o conceito existente na mente do escritor. Como diz Chartier (2014), o encontro da mão com a mente do autor. Por outro lado, como concepção, o modelo do Roget'sThesaurus serviu ao ensino da língua inglesa, em pesquisas de natureza linguística e filológica e nos indicou a importância das categorias ou facetas utilizadas desde sua concepção em 1850. O Visual Roget mostra as seis categorias presentes na primeira edição: relações abstratas; espaço; matéria; intelecto; vontade; e, afeição.

Figura 2 - Categorias principais do Roget's Thesaurus

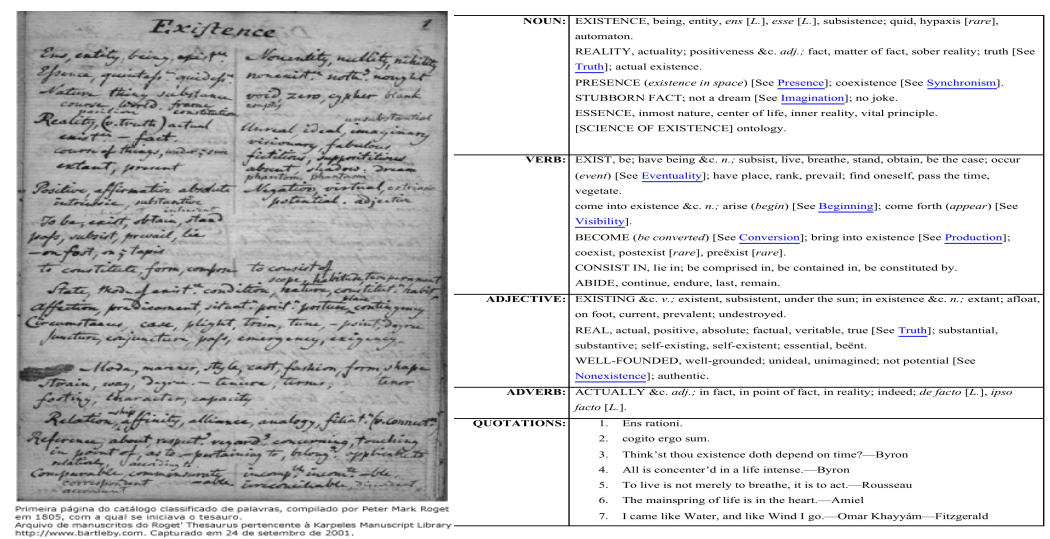

Fonte: Karpeles Manuscript Library, 2001

Estruturas arbóreas, radiculares ou rizomáticas, lineares, cartográficas, animadas mostram as possibilidades visuais que temos hoje não só para descrever as relações entre conceitos, como para permitir a integração destas entre mapas conceituais e ontologias. Outros modelos de tesauros visuais, que podem ser construídos sob qualquer assunto, utilizam o modelo do Roget's

Inf. Inf., Londrina, v. 22, n. 2, p. 67 - 83, maio/ago., 2017. http:www.uel.br/revistas/informacao/ 
Thesaurus em relação as categorias da gramática: nomes; adjetivos; verbos; e advérbios. Um outro exemplo de síntese conceitual por mapas é o da Enciclopédia Einaudi que apresenta, ao final de cada um de seus 41 volumes (edição portuguesa), temas aproximados do ponto de vista da informação (aprendizagem-cérebro-categoria), já nos encaminhando para a lógica do fluxo.

\section{LÓGICA DO FLUXO: ONTOLOGIAS, INFORMAÇÃO, DISCURSIVIDADE}

Com base em Rafael Capurro (1991) sobre os paradigmas representacional, comunicacional e platônico/informação em si própria e, também, sobre a ética da informação, a memória na sociedade da informação, bem como na ideia de fluxo informacional (Barreto,1998), a lógica do fluxo que apresento diz respeito ao diálogo inicial travado entre temas da Organização do Conhecimento como, por exemplo, "Informação, memória e documento". Essas três palavrinhas-chave embalaram a pesquisa-tese "O sentido e o significado de documento para a memória social" defendida em 1997, sob orientação de Rosali Fernandez de Souza.

A principal questão levantada já ensaiava um discurso sobre a importância do diálogo entre saberes, sobre o objeto efêmero e circunstancial do ponto de vista da memória social e abria a discussão para o debate sobre a impossibilidade de organizar o conhecimento de forma unicamente hierárquica, bem como sobre a impossibilidade de preservar toda a memória da humanidade.

Com a parceria da antropóloga Regina Abreu, e no curso de uma reforma curricular para implantar o doutorado em Memória Social, estendi o valor documental dos objetos ao valor patrimonial. Afinal, a minha experiência como bibliotecária já apontava a biblioteca e a biblioteconomia como devedoras de dois conceitos esquecidos com o advento da Ciência da Informação: memória e patrimônio. Na lógica do fluxo informacional, entendi que as bibliotecas são lugares de memória, como nos mostrou Pierre Nora () e lugares

Inf. Inf., Londrina, v. 22, n. 2, p. 67 - 83, maio/ago., 2017. 
de saber, como o demonstra Cristian Jacob (2014) e também que, em determinadas circunstâncias, são patrimônios locais e internacionais, como nos sugere a Unesco. A lógica do fluxo representa, assim, o alargamento das fronteiras deste campo teórico, prático e político.

O uso de Mapas Conceituais como estratégia de visualizar as relações entre os conceitos não se restringe a questões meramente estéticas mas, sobretudo, ao registro desses estudos de forma que possam ser lidos por softwares e por humanos e, mais importante, porque ao possuírem natureza interoperável, permitem produção colaborativa em tempo real. O software utilizado para a construção dos mapas produzidos e utilizados neste artigo é o CmapTools (2017), plataforma de acesso livre do Institute for Human and Machine Cognition (IHMC).

Figura 3 - Informação, Memória e Patrimônio

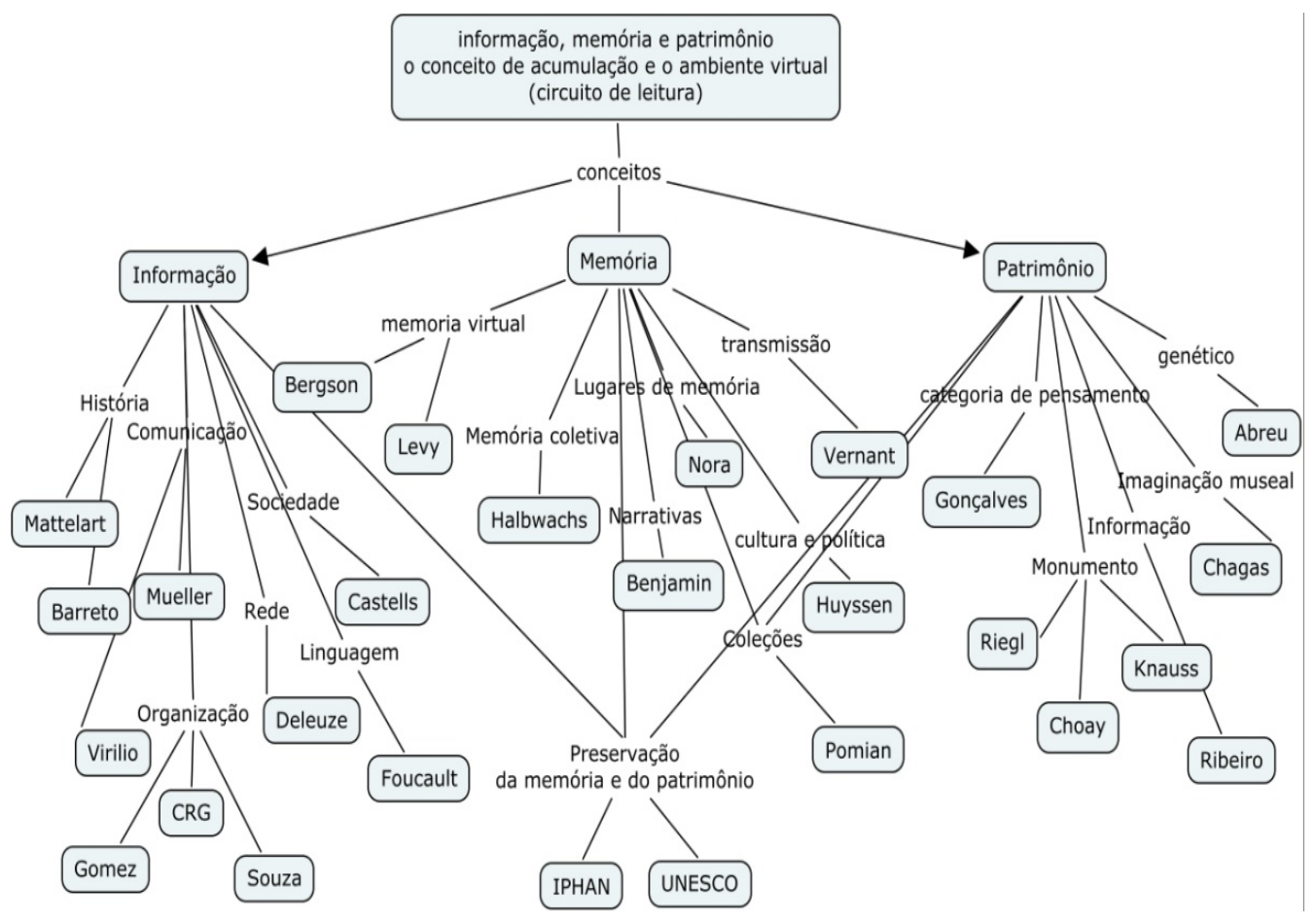

Fonte: a autora

Inf. Inf., Londrina, v. 22, n. 2, p. 67 - 83, maio/ago., 2017 http:www.uel.br/revistas/informacao/ 
Vera Dodebei

Organização do conhecimento em shortcuts: memórias de pesquisa sob o sprit benjaminiano

A necessidade de compreender a cultura do registro no meio social fez com que se iniciassem pesquisas sobre a cultura digital, apesar de termos consciência, como disse Gilberto Gil, que esse adjetivo (digital) é meramente operacional, em razão de que em futuro próximo ele abarcaria todos os objetos.

Ainda sob uma combinação das lógicas de assuntos, conceitos e fluxos, a representação discursiva vem nos ajudando a compreender e a descrever discursivamente campos ultra específicos como podemos observar no mapa conceitual sobre a Memória Social e, mais especificamente, no conceito de Justa Memória de Paul Ricœur (2007). Com base na estrutura discursiva da obra de Paul Ricoeur "Memória, História e Esquecimento", o mapa construído como planejamento didático para a disciplina Memória Social e Instituição nos leva a pensar que estes fragmentos de narrativas se inserem também em um banco de dados interoperável.

Figura 4 - Paul Ricœur

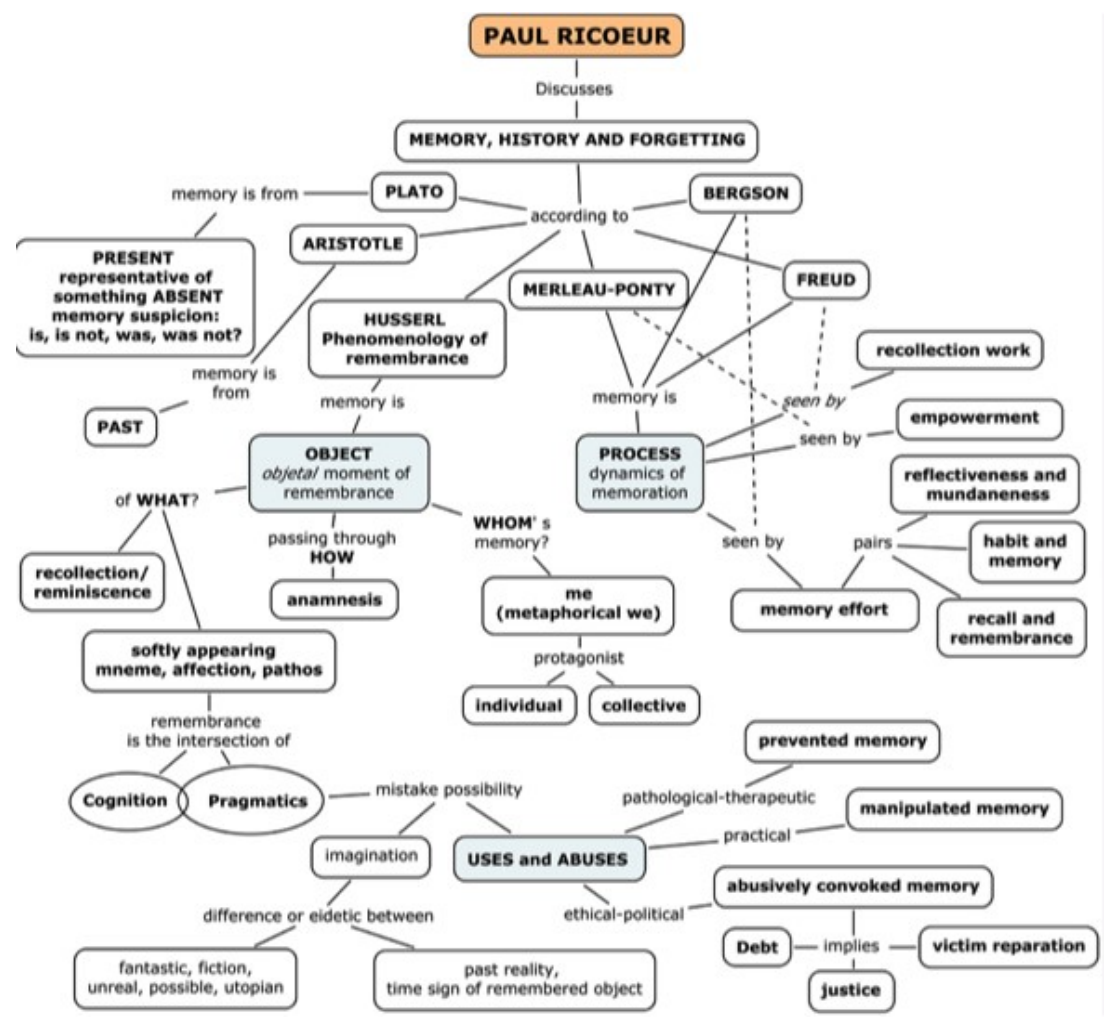

Fonte: DODEBEI, Vera; ORRICO, Evelyn, 2014

Inf. Inf., Londrina, v. 22, n. 2, p. 67 - 83, maio/ago., 2017. http:www.uel.br/revistas/informacao/ 
A inteligência artificial vem contribuindo para auxiliar a seleção e recuperação de informações e de registros de acervos, provocando, de certo modo, uma diminuição da massa documental que, como diz Pierre Nora (1993), sobre esta não queremos nos separar por tributo à memória total.

A construção de ontologias de domínio é um campo que, com a aceleração do tempo e a facilidade de armazenarmos quantidades inimagináveis de terabytes no espaço virtual, vem contribuir para a salvaguarda de acervos seletivos. Com a ajuda da inteligência artificial, o humano e a máquina podem ler relações conceituais e obter respostas lógicas a perguntas feitas ao sistema de informação.

\section{LÓGICA DO MEIO AMBIENTE: BIG DATA, ECOLOGIA E DIVERSIDADE}

Em defesa a um novo paradigma que dê conta da organização de conhecimentos "em crise" Henrique Leff (2012), diz que o saber ambiental constrói-se no encontro de visões de mundo, na abertura do saber para a diversidade, a diferença e a outridade. Reforça, ainda, que a crise ambiental é uma crise do conhecimento. Se o que está em jogo é a apropriação social da natureza e a construção de um futuro sustentável, devemos prestar mais atenção às multirreferências e menos às monorreferencialidades. Nem o ser é uno, nem o saber o é.

Neste momento, a compreensão que nossa pesquisa busca realizar diz respeito aos dejetos, de cunho eletrônico, que aqui chamamos de restos, ou lixo digital espalhado no ciberespaço, bem como os seus rastros ou lembranças auráticas de vestígios de memória que podem ser, de certo modo, reciclados. No entanto, para localizar estes restos memoriais estaremos lidando não mais com coleções de documentos, mas com dados digitais. A quantidade de dados que lançamos diariamente no ciberespaço constitui hoje uma área específica de conhecimento denominada de Big Data.

Inf. Inf., Londrina, v. 22, n. 2, p. 67 - 83, maio/ago., 2017. 
Para enfrentar esse universo de dados armazenado em 'nuvens' vem se destacando no campo da pesquisa científica uma subárea denominada 'Análise de Dados' que tem por objetivo selecionar dessa enorme massa de bytes aqueles dados que podem responder a uma determinada hipótese de pesquisa. A qualidade dos dados a serem escolhidos vai levar em conta o modo como os objetos digitais foram criados: dados fluidos ou de caráter meramente comunicacional e, portanto, efêmeros; ou dados protegidos por camadas de informações que assegurem sua autenticidade com propósito memorial.

Yamaoka e Gauthier (2013), em artigo que busca responder à questão o que é um objeto digital? - consideram que, fora a questão terminológica em que aparecem os termos - arquivo de computador (file), documento digital, artefato digital, recurso digital e material digital como sinônimos de objeto digital, é importante compreender a estrutura de tal objeto. Para isto, valem-se de Thibodeau que define objeto digital como um objeto de informação, de qualquer tipo e formato expresso sob a forma digital e que compreende três categorias informacionais: objeto físico, objeto lógico e objeto conceitual:

a) objeto físico - o objeto digital é simplesmente uma inscrição de sinais em uma mídia; O meio físico determina uma convenção para a gravação de dados com densidade e tamanho de blocos diferentes. A inscrição física é independente do significado e, portanto, o computador não sabe se o objeto contém um documento em linguagem natural ou uma foto, por exemplo. A inscrição física não implica em sintaxe, morfologia ou semântica;

b) objeto lógico - como objeto lógico o objeto digital é reconhecido e processado por software. No nível lógico a gramática é independente da inscrição física. Um software aplicativo reconhece o formato do objeto, os tipos de dados como os códigos American Standard Code for Information Interchange (ASCII) e os dados de formatação como, por exemplo, o tipo de fonte, os recuos e os estilos; e,

c) objeto conceitual - como objeto conceitual o objeto digital é reconhecido e entendido por uma pessoa ou, em alguns casos, reconhecido e processado por um software. É o objeto "do mundo real", reconhecido como uma unidade significativa de informação, tal como um livro, um contrato, um mapa ou uma fotografia. (THIBODEAU, 2002, apud YAMAOKA; GAUTHIER, 2013, p.82-83)

Inf. Inf., Londrina, v. 22, n. 2, p. 67 - 83, maio/ago., 2017. 
O mapa conceitual construído pelos referidos autores organiza os conceitos principais da teoria dos objetos digitais, incluindo o contexto no qual essa discussão acontece, que é a da preservação digital.

Figura 5 - Mapa baseado no modelo de Thibodeau e de outros autores

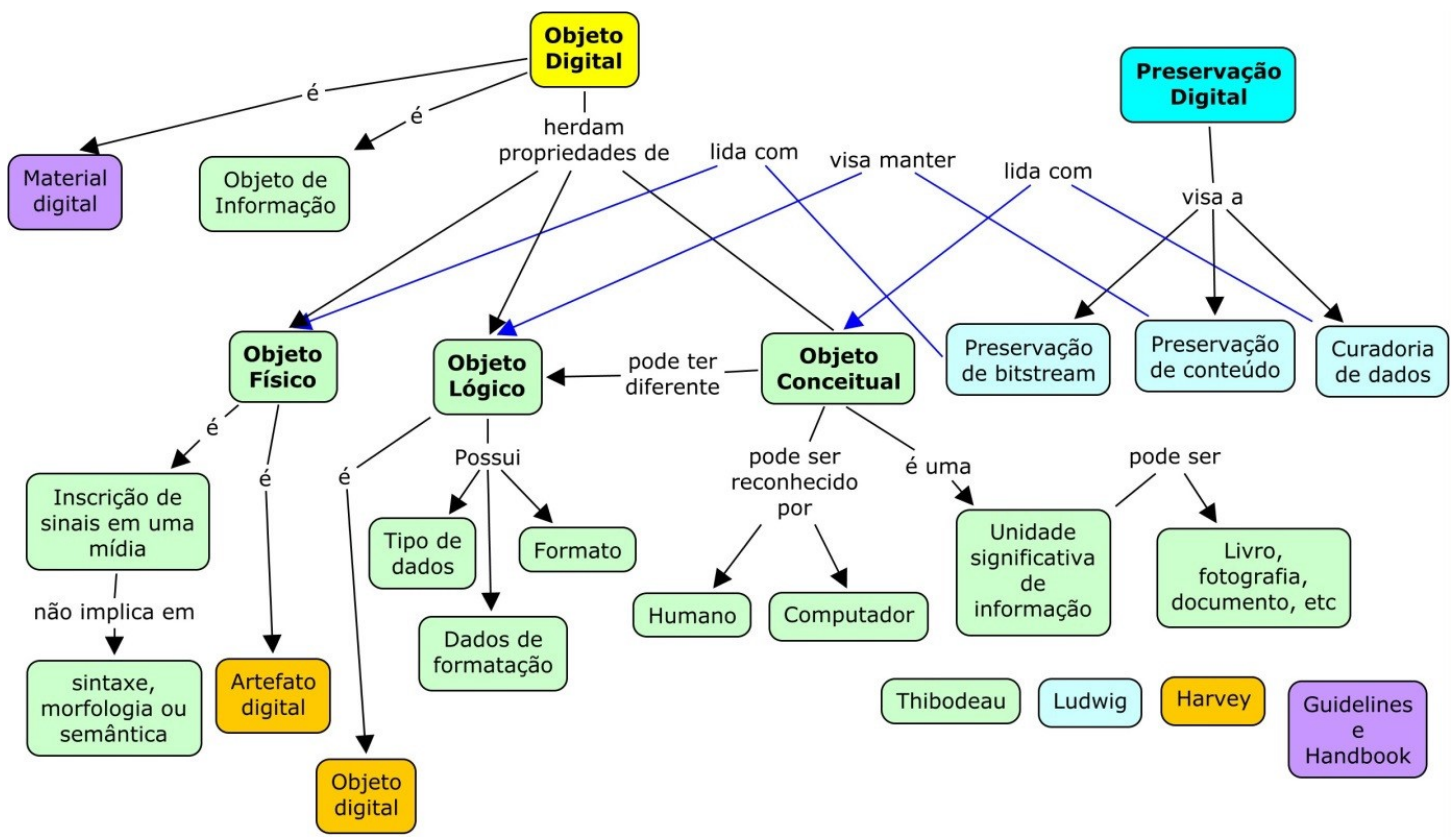

Fonte: YAMAOKA; GAUTHIER, 2013.

A reciclagem e, particularmente, o reuso parecem ser as formas ecológicas de manipulação dos objetos digitais que constituem os bancos de dados criados no ciberespaço. As experiências de uso nessa nova biblioteca de terabytes - a web - veem encontrando usuários, justamente no campo da pesquisa científica: (a) objeto conceitual / dados de pesquisa / curadoria de dados/ reúso intelectual; (b) objeto lógico / formatos / preservação de conteúdo / reúso técnico; e, (c) objeto físico / cadeia de bits / Preservação de bitstream/ identidade técnica. (YAMAOKA; GAUTHIER, 2013)

Sobre a possibilidade de encontrarmos rastros memoriais nos objetos digitais, essa é ainda uma hipótese não confirmada. O que vimos realizando são experimentos específicos sobre os objetos digitais (narrativas) postados em aplicativos e as análises a partir de técnicas netnográficas ou de

Inf. Inf., Londrina, v. 22, n. 2, p. 67 - 83, maio/ago., 2017. 
observação participante que podem ser feitas em relação ao comportamento dos internautas sobre guardar ou descartar os objetos.

Em relação aos rastros ou lembranças auráticas, podemos citar o interesse que nossos alunos vêm demonstrando para estudar temas, no âmbito de uma espécie de ecologia social, sobre a invisibilidade e as narrativas digitais de moradores de rua; a educação patrimonial e a contracultura na arte de grafitar; os autos de resistência e as narrativas digitais na luta e no luto de mães cujos filhos foram assassinados nas guerras urbanas; o direito de esquecer nas redes sociais; a função patrimonial das bibliotecas nacionais, entre outros.

\section{ALGUMAS CONSIDERAÇÕES}

Os indicadores e pressupostos de que há uma mudança, em relação ao compromisso social de compartilhar memórias por parte das instituições armazenadoras de conhecimentos na virada do século XX para o XXI, pode ser verificado quando estas se deslocam: (a) do mundo memorial (representado pelo que ocorreu no passado) ao mundo da pluralidade de saberes (mundo contemporâneo); (b) da disseminação do produto do conhecimento à disseminação do processo de construção desse conhecimento, em função das tecnologias eletrônicas de armazenamento de grandes massas de dados; (c) da acumulação contínua de informações (mundo inscrito) à redução proporcionada por re-uso e reciclagem (mundo sustentável); e, (d) da retenção e manutenção do conhecimento como regra (informações estáveis) à seleção dos saberes que devem permanecer efêmeros (informações fluidas) por suas comunidades produtoras.

As bibliotecas foram organizadas por classificações que nos ajudavam a encontrar um livro nas estantes. Em seguida, nas bases de dados referenciais, já em formato eletrônico, podíamos recuperar o item desejado graças aos metadados atribuídos aos objetos digitais por indexadores. Construíamos nossas hipóteses de pesquisa e a tarefa primeira era a revisão bibliográfica

Inf. Inf., Londrina, v. 22, n. 2, p. 67 - 83, maio/ago., 2017. 
sobre o tema específico. Para discutir a Organização do Conhecimento no tempo da Big Data muitas pesquisas precisam ainda ser desenvolvidas para além da interdisciplinaridade. O diálogo mais amplo entre os saberes vai exigir a reunião de pesquisadores de campos diversos de conhecimentos científicos, de conhecimentos tradicionais e de culturas ímpares.

\section{REFERÊNCIAS}

ÁRVORES DE MÃOS-DADAS (Imagem de fundo). Disponível em: https://www.google.com.br/search?q=\%C3\%A1rvores+de+m\%C3\%A3os+dada s\&client=safari\&channel=mac bm\&source $=$ Inms\&tbm=isch\&sa $=X \&$ ved $=0 a h U K$ Ewjc9c_spMDUAhWIh5AKHc0XCIYQ_AUICigB\&biw=1046\&bih=688 Acesso em: 16 jun. 2016.

BARRETO, Aldo de A. Mudança estrutural no fluxo do conhecimento: a comunicação eletrônica. Ci. Inf., Brasília, v. 27, n. 2, p. 122-127, maio/ago, 1998. Disponível em: http://www.scielo.br/pdf/ci/v27n2/2729803.pdf. Acesso em 25 de ago. 2017.

BRASIL. Ministério do Trabalho. Secretaria de Emprego e Salário. Classificação brasileira de ocupações. Brasília: SINE, 1977.

BENJAMIN, Walter. Passagens. Trad. Irene Aron; Cleonice Mourão. Belo Horizonte: Editora UFMG, 2007.

CAPURRO, Rafael. Foundations of information science: review and perspectives [online]. 1999. Disponível em: http://www.capurro.de/tampere91.htm. Acesso em 5 ago. 2017. (versão atualizada e ampliada do texto original - What is information science for? apresentado na International Conference on conceptions of library and information science. Tempere, Finland: University of Tempere, 26-28 August, 1991.

CHARTIER, Roger. A mão do autor e a mente do editor. São Paulo: Editora UNESP, 2014.

CmapTools. Disponível em: http://cmap.ihmc.us/ Acesso em 26 ago. 2017.

DODEBEI, Vera; ORRICO, Evelyn. Knowledge in social memory: empirical experiment for a domain conceptual-discursive mapping. Advanves in Knowledge Organisation, v. 14, p. 65-73, 2014.

Inf. Inf., Londrina, v. 22, n. 2, p. 67 - 83, maio/ago., 2017. 
JACOB, Chistian. Qu'est-ce qu'un lieu de savoir? Marseille: OpenEdition, 2014.

KARPELES Manuscript Library. Roget's Thesaurus manuscript archives. Disponível em: <http://www.Bartley.com> Acesso em 24 set. 2001.

KUHN, Thomas S. A estrutura das revoluções científicas. São Paulo: Perspectiva, 2001.

LEFF, Enrique. Aventuras da epistemologia ambiental: da articulação da ciências ao diálogo de saberes. São Paulo: Cortez, 2012.

NORA, Pierre. Entre memória e história: a problemática dos lugares. Proj. História, São Paulo, n. 10, p. 7-28, dez, 1993.

RICOEEUR, Paul. Memória, história e esquecimento. Campinas, SP: Editora da UNICAMP, 2007.

RANGANATHAN, S. R. Colon classification. Demy 6vo., 1933.

ROGET, Peter Mark. Roget's Thesaurus. [London: Peter Mark Roget, 1852.]

YAMAOKA, Eloi Juniti; GAUTHIER, Fernando Ostuni. Objetos digitais: em busca da precisão conceitual. Inf. Inf., Londrina, v. 18, n. 2, p. 77 - 97, maio/ago. 2013. Disponível em: http:www.uel.br/revistas/informacao/83. Acesso em 26 ago. 2017.

Title

Knowledge Organization in shortcuts: research notes under benjaninian sprit

\begin{abstract}
Introduction: Under the 'holding hands' metaphor, the concepts, means of transmission and the uses of memory data are discussed in four shortcuts from a historical point of view: philosophy, science, information and ecology. Objectives: To present research notes in the field of knowledge organization. Methodology: It was used conceptual relations networks built by maps with the support of CmapTools software. Results: As main results, it presents indicators and assumptions that there is already a change, in relation to the social commitment to share memories from institutions that store and organize knowledge. Conclusions: It concludes with the observation that the quality of data to be chosen to feed collections of objects selected as memory should take into account the way in which the digital objects were created: fluid data or merely communicational and therefore ephemeral data; or data protected by information layers that assure its authenticity for the purpose of memories reusing.
\end{abstract}

Inf. Inf., Londrina, v. 22, n. 2, p. 67 - 83, maio/ago., 2017. http:www.uel.br/revistas/informacao/ 
Vera Dodebei

Organização do conhecimento em shortcuts: memórias de pesquisa sob o sprit benjaminiano

Keywords: Knowledge Organization. Memory. Digital object.

\section{Título}

Organización del Conocimiento en shortcuts: memorias de investigaciones bajo el sprit benjaminiano

\section{Resumen}

Introducción: Bajo la metáfora del 'árbol de mano dadas', se discuten los conceptos, los medios de transmisión y los usos de los registros de memoria en cuatro atajos, pasajes, pasarelas o shortcuts de naturaleza temporal e histórica: filosofía, ciencia, información y ecologia. Objetivos: presentar memorias de investigaciones en el campo de la organización del conocimiento. Metodología: Se utilizaron redes de relaciones conceptuales construidas por mapas con el apoyo del software CmapTools. Resultados: Como resultados principales, presenta indicadores y presupuestos de que ya hay un cambio, en relación al compromiso social de compartir memorias por parte de las instituciones almacenadoras de conocimientos. Conclusiones: Concluye con la observación de que la calidad de los datos a ser elegidos para alimentar colecciones de objetos seleccionados como memoria deberá tener en cuenta el modo como los objetos digitales fueron creados: datos fluidos o de carácter meramente comunicacional y, por lo tanto, efímeros; o datos protegidos por capas de informaciones que aseguren su autenticidad con propósito de reutilización memorial.

Palabras claves: Organización del conocimiento. Memoria. Objetos digitales.

Recebido: 10.03.2017

Aceito: 25.08 .2017

Inf. Inf., Londrina, v. 22, n. 2, p. 67 - 83, maio/ago., 2017. 